\title{
Profiling Occupant Behaviour in Danish Dwellings using Time Use Survey Data
}

\author{
Barthelmes, V.M.; Li, R.; Andersen, Rune Korsholm; Bahnfleth, W.; Corgnati, S.P.; Rode, Carsten
}

Published in:

Energy and Buildings

Link to article, DOI:

10.1016/j.enbuild.2018.07.044

Publication date:

2018

Document Version

Peer reviewed version

Link back to DTU Orbit

Citation (APA):

Barthelmes, V. M., Li, R., Andersen, R. K., Bahnfleth, W., Corgnati, S. P., \& Rode, C. (2018). Profiling Occupant Behaviour in Danish Dwellings using Time Use Survey Data. Energy and Buildings, 177, 329-340.

https://doi.org/10.1016/j.enbuild.2018.07.044

\section{General rights}

Copyright and moral rights for the publications made accessible in the public portal are retained by the authors and/or other copyright owners and it is a condition of accessing publications that users recognise and abide by the legal requirements associated with these rights.

- Users may download and print one copy of any publication from the public portal for the purpose of private study or research.

- You may not further distribute the material or use it for any profit-making activity or commercial gain

- You may freely distribute the URL identifying the publication in the public portal 


\section{Accepted Manuscript}

Profiling Occupant Behaviour in Danish Dwellings using Time Use Survey Data

V.M. Barthelmes, R. Li, R.K. Andersen, W. Bahnfleth, S.P. Corgnati, C. Rode

PII:

DOI:

Reference:

To appear in:

Received date:

Revised date:

Accepted date:
S0378-7788(17)34204-4

https://doi.org/10.1016/j.enbuild.2018.07.044

ENB 8715

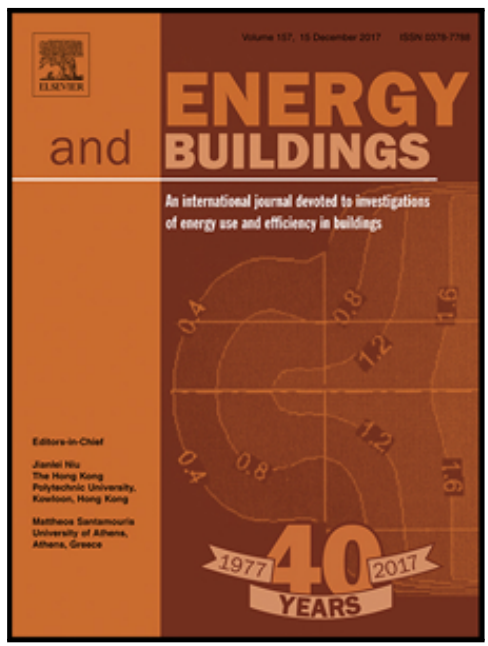

\section{Energy \& Buildings}

29 December 2017

19 July 2018

22 July 2018

Please cite this article as: V.M. Barthelmes, R. Li, R.K. Andersen, W. Bahnfleth, S.P. Corgnati , C. Rode, Profiling Occupant Behaviour in Danish Dwellings using Time Use Survey Data, Energy \& Buildings (2018), doi: https://doi.org/10.1016/j.enbuild.2018.07.044

This is a PDF file of an unedited manuscript that has been accepted for publication. As a service to our customers we are providing this early version of the manuscript. The manuscript will undergo copyediting, typesetting, and review of the resulting proof before it is published in its final form. Please note that during the production process errors may be discovered which could affect the content, and all legal disclaimers that apply to the journal pertain. 


\title{
Profiling Occupant Behaviour in Danish Dwellings using Time Use Survey Data
}

\author{
V. M. Barthelmes ${ }^{\text {a,b,* }}$, R. Li ${ }^{\text {a }}$, R. K. Andersen ${ }^{\text {a }}$, W. Bahnfleth ${ }^{\text {c }}$, S. P. Corgnati ${ }^{\text {b }}$, and C. Rode ${ }^{\text {a }}$ \\ ${ }^{a}$ International Centre for Indoor Environment and Energy \\ Technical University of Denmark, Nils Koppels Allé Building 402, 2800 Kgs Lyngby, Denmark \\ ${ }^{b}$ Department of Energy (DENERG) \\ Politecnico di Torino, Corso Duca degli Abruzzi 24, 10129 Turin, Italy \\ ${ }^{c}$ Indoor Environment Center, Department of Architectural Engineering \\ The Pennsylvania State University, University Park, PA 16802, USA
}

\begin{abstract}
The human interaction with the building is a key cause of uncertainty when predicting energy consumption of buildings. Building occupants affect building energy use directly and indirectly by interacting with building energy systems, for example, by adjusting thermostats, switching lights on/off, using electrical devices and opening/closing windows. The occupants' daily activity profiles and occupancy patterns clearly shape the timing and magnitude of energy demand in households. Modelling energy-related human activities throughout the day, therefore, is a crucial task for prediction of energy use and, consequently, to reduce the gap between real and predicted building energy use.

This study modelled data gathered in the diary-based Danish Time Use Survey (TUS) 2008/09 of 9,640 individuals from 4,679 households. Individuals' daily activities were logged in 10-minute time increments for $24 \mathrm{~h}$, starting and ending at 04:00, during both weekdays and weekends. The aims of this study were to (i) profile energy-related daily activities of occupants during different seasons and weekdays/weekends (ii) investigate time-related characteristics of activities such as starting and ending times and durations, and (iii) profile occupancy patterns for weekdays/weekends for different household types. The outcomes provide valuable input for building energy simulation for bridging the gap between simulated and real energy consumption in the Danish residential sector; typical occupancy profiles for different household types for different days of the week are freely available online [1].
\end{abstract}

Key words: Occupant behaviour, occupancy, Time Use Survey, residential buildings

\section{INTRODUCTION}

In the European energy expenditure balance, the residential building sector is a major consumer of energy and has therefore become a focus for various types of energy consumption efforts [2]. Within the wider building energy research community and among energy-aware designers, dynamic Building Energy Performance Simulations (BEPS) are increasingly used to gain a more precise understanding of the underlying processes of energy flows and to optimize building energy use. BEPS have become indispensable instruments to predict building energy use and are considered valuable design-support tools for energy experts in the building sector. However, simulation results are prone to errors since many of the fundamental phenomena are not sufficiently understood. A major challenge in simulation tool development and application is how to deal with difficulties associated with a large variety of parameters and complexity of factors such as non-linearity, discreteness, and uncertainty [3]. The stochastic nature of the human interaction with the building is a key aspect of uncertainty for building design, energy diagnosis, performance evaluation, and building energy simulation due to its significant impact on real energy use and indoor environment in buildings. It has attracted research attention in the International Energy Agency (IEA EBC 
Annex 66) [4]. In addition, extended literature reviews and state-of-the-art analyses highlight that the accurate modelling of occupant behaviour is essential to bridging the gap between predicted and actual energy performance of buildings [5-9] Many studies have documented the need for comprehensive and validated stochastic models predicting residential occupancy and activities, as well as the variations between individuals and households [10-12]. For example, Larsen et al. [11] carried out an in-depth analysis on how occupants influence the energy consumption of Danish residential buildings and highlighted how the new demand for sustainability will inevitably increase the influence of the occupants' presence and interaction on energy use. Therefore, detailed modelling of these processes is necessary to predict energy use, indoor climate and in particular peak loads of heating, ventilation and air conditioning for system dimensioning.

In this context, occupants' activities evidently shape the timing of building energy use throughout the day. Diary-based surveys on how occupants spend their time during the day can help to shape occupancy profiles and energy-related activities. National time use surveys (TUS) have been carried out at national level since the early 1970s. The first TUS were conducted in developing countries in Europe. They were designed to understand and assess progress in lifestyles, focusing mainly on time spent for leisure, transport, and work. The first TUS in developing and transitional countries were conducted in the late 1990s, with the main objective being to measure the gender gap in paid and unpaid work. By 2015, nearly a hundred surveys for 65 countries were available for in-depth analyses [13,14].

Although TUS data have been used predominantly for answering research questions related to social aspects, work, and economics, they are becoming an essential data source for energy-related occupant behaviour modelling as well (Table 1). As Schipper et al. [15] first stated, to gain a deeper understanding about the impact of different lifestyles on energy use it is necessary to understand interdependencies between time use and energy consumption. Wilke [16,17], for instance, developed stochastic models based on the French TUS to predict time-dependent residential occupancy and activities, relating the use of electrical appliances to the activities performed. Yu et al. [18] used data collected in a household TUS in Beijing to develop a household time-use and energy-consumption model, which incorporates multiple behavioural interactions. Torriti [19] used the British TUS to assess how dependent energy-related social practices in the household are in relation to the time of the day. They analysed the 2005 UK TUS and made use of statistically derived time dependence metrics for six social practices, including preparing food, washing, cleaning, washing clothes, watching TV and computer usage. Other studies modelled TUS data to explore the temporal change in laundry practices and related implications on the flexibility of energy demand [20] or to generate myriad schedule data of each inhabitant's behaviour at a fine time resolution for time-series cooling load calculation [21,22].

Indeed, next to the exploration of TUS data for establishing a link between occupants' activities and energy consumption, time use data have been used most frequently in the development of high resolution occupancy profiles for different countries. Richardson et al. [23] presented a thorough and detailed method for generating realistic occupancy data for UK households, based upon surveyed time-use data describing what people do and when. The approach presented generates statistical occupancy time-series data with a tenminute resolution and takes account of differences between weekdays and weekends. The model also indicates the number of occupants that were active within a house at a given time. Aerts et al. [24] developed a methodology for modelling domestic occupancy patterns based on the Belgian TUS (2005). Buttita et al. [25] used the UK 2000 TUS for demonstrating a methodology that permits to generate occupancy patterns that can be representative for different archetype building models.

Some of the existing studies show that TUS data represents a significant resource by validating their TUSbased approaches against field measurements. Widén et al. [26], for instance, modelled time-use data for constructing load profiles for household electricity and domestic hot water based on Swedish TUS data. They also provided validation against detailed, end-use specific electricity measurements in a small sample of households and revealed that the model for household electricity reproduces hourly load patterns with preservation of important qualitative features. Fischer et al. [27] modelled electric load profiles with high 
time resolution based on the German TUS and validated their model against field data from 430 households; the results showed an accuracy of $91 \%$.

The range of above-mentioned studies clearly shows how TUS data can be used to model and analyse occupant behaviour in the field of building energy use. In countries with growing electricity generation from renewable energy sources, gaining better knowledge of occupants' time use in households and related energy use at a national scale becomes a crucial task in order to respond to challenges related to demand-response modelling. However, in the Danish building energy research community, TUS data have not been analysed from the perspective of energy usage. Its potential usability for modelling energy- and behavioural-related processes in this context needs still to be thoroughly explored. Furthermore, to the best knowledge of the authors, there are no existing studies present tailored approaches for modelling building occupants' presence in Danish households.

In light of the foregoing discussion, the aim of this paper was to investigate time use in the Danish population and to understand if the Danish TUS data are applicable for further research on modelling behavioural patterns in households. In particular, we introduced and analysed the latest diary-based Danish TUS in order to (i) shape energy-related daily activity profiles of occupants during different seasons and weekdays/weekends, (ii) investigate time-related factors of activities such as startíng, ending times and durations, and (iii) profile occupancy patterns for weekdays/weekends and different household types. These occupancy profiles for different household and day types are freely available online for implementation in BEPS in the academic and industrial sector.

Table 1: Studies that employed TUS data in occupant behaviour-related building energy analysis.

\begin{tabular}{|c|c|c|c|c|}
\hline Authors/year & TUS & Respondents & Time resolution & Modelling Purpose \\
\hline Richardson et al. [23] & $\begin{array}{l}\text { UK TUS, 2000, "The } \\
\text { United Kingdom } 2000 \\
\text { Time Use Survey" }\end{array}$ & $x_{-1}$ & 10 minutes & Occupancy \\
\hline Wilke [16][17] & French TUS 1998/1999 & $\begin{array}{l}\text { 15,441 individuals, } \\
7,949 \text { households }\end{array}$ & 10 minutes & $\begin{array}{l}\text { Occupancy, activities, } \\
\text { electricity demand }\end{array}$ \\
\hline Yu et al. [18] & $\begin{array}{l}\text { Beijing TUS, China, } \\
2010\end{array}$ & $\begin{array}{l}10 \text { residential districts, } \\
611 \text { households, } 1,314 \\
\text { households members* }\end{array}$ & $\begin{array}{l}\text { Weekdays, weekends, } 6 \\
\text { clustered activities (out } \\
\text { of } 12 \text { ) }\end{array}$ & $\begin{array}{l}\text { Household time-use and } \\
\text { energy-consumption } \\
\text { model }\end{array}$ \\
\hline Torriti [19] & UK TUS 20 & 3,554 individuals & $\begin{array}{l}10 \text { minutes, only } \\
\text { weekdays }\end{array}$ & $\begin{array}{l}\text { Time dependency of } \\
\text { energy-related social } \\
\text { practices }\end{array}$ \\
\hline $\begin{array}{l}\text { Tanimoto et al. } \\
\text { Tanimoto et al. }\end{array}$ & $\begin{array}{l}\text { National Survey on } \\
\text { Living Time Schedule, } \\
\text { NHK (Nippon Hoso } \\
\text { Kyokai) Laboratory, } \\
2000+\text { "Survey on } \\
\text { Time Use and Leisure } \\
\text { Activities" (Statistics } \\
\text { Bureau of the Ministry } \\
\text { of Internal Affairs and } \\
\text { Communication) }\end{array}$ & - & $\begin{array}{l}\text { Weekdays, Saturday, } \\
\text { Sunday, } 15 \text { minutes }\end{array}$ & $\begin{array}{l}\text { Generation of } \\
\text { inhabitants' behaviour } \\
\text { schedules for cooling } \\
\text { load calculation }\end{array}$ \\
\hline $\begin{array}{l}\text { Widén et al. [26] } \\
\text { Widén et al. [29] }\end{array}$ & $\begin{array}{l}\text { Swedish TUS, } 1996 \text { - } \\
\text { TU-SCB-1996 data set }\end{array}$ & $\begin{array}{l}426 \text { persons in } 103 \\
\text { detached houses and } 64 \\
\text { apartments }\end{array}$ & $\begin{array}{l}1 \text { weekday and } 1 \\
\text { weekend day, } 1-5 \\
\text { minutes }\end{array}$ & $\begin{array}{l}\text { Generation of load } \\
\text { profiles for household } \\
\text { electricity and domestic } \\
\text { hot water } \\
\text { Development of a three- } \\
\text { state non-homogeneous } \\
\text { Markov chain and } \\
\text { bottom-up approach for } \\
\text { modelling domestic } \\
\text { lighting demand }\end{array}$ \\
\hline Aerts et al. [24] & $\begin{array}{l}\text { Belgian TUS and } \\
\text { Household Budget }\end{array}$ & $\begin{array}{l}6,400 \text { respondents, } \\
3,455 \text { households }\end{array}$ & $\begin{array}{l}1 \text { weekday, } 1 \text { weekend } \\
\text { day, } 7 \text { typical }\end{array}$ & Occupancy \\
\hline
\end{tabular}




\begin{tabular}{|c|c|c|c|c|}
\hline & Survey (HBS), 2005 & & $\begin{array}{l}\text { occupancy patterns, } 10 \\
\text { minutes }\end{array}$ & \\
\hline Lauretis et al. [30] & $\begin{array}{l}\text { French TUS 2009/2010 } \\
\text { and French household } \\
\text { expenditure survey }\end{array}$ & 27,903 time diaries & 10 minutes & $\begin{array}{l}\text { Disparities in activity } \\
\text { patterns and related } \\
\text { energy consumptions } \\
\text { and expenditures }\end{array}$ \\
\hline $\begin{array}{l}\text { Jalas and Juntunen } \\
\text { [31] }\end{array}$ & $\begin{array}{l}\text { Finnish TUS 1987/88, } \\
\text { 1999/2000, 2009/2010, } \\
\text { Finnish household } \\
\text { expenditure surveys } \\
\text { from 1990, 1998, } 2006\end{array}$ & Mixed & $\begin{array}{l}10 \text { minutes during day, } \\
20 \text { minutes during } \\
\text { night, } 14 \text { clustered } \\
\text { activity categories (out } \\
\text { of } 26 \text { ) }\end{array}$ & $\begin{array}{l}\text { Energy and carbon } \\
\text { intensity of household } \\
\text { activities }\end{array}$ \\
\hline Chiou et al. [32] & American TUS 2006 & $\begin{array}{l}\text { Ca. } 13,000 \text { individual } \\
\text { diaries }\end{array}$ & $\begin{array}{l}\text { No fixed time step, } 403 \\
\text { activity codes, } \\
\text { weekday, weekend }\end{array}$ & $\begin{array}{l}\text { High spatial resolution } \\
\text { model of energy use }\end{array}$ \\
\hline Fischer et al. [27] & German TUS 2002 & $\begin{array}{l}\text { 14,000 individuals, } \\
5,200 \text { households }\end{array}$ & $\begin{array}{l}10 \text { minutes, two } \\
\text { weekdays and one } \\
\text { weekend-day }\end{array}$ & $\begin{array}{l}\text { Modelling electric load } \\
\text { profiles with high time } \\
\text { resolution }\end{array}$ \\
\hline Buttita et al. [25] & UK TUS, 2000 & $\begin{array}{l}11,700 \text { individuals, } \\
6,500 \text { households }\end{array}$ & $\begin{array}{l}10 \text { minutes, we } \\
\text { weekend day }\end{array}$ & $\begin{array}{l}\text { Clustering of household } \\
\text { occupancy profiles for } \\
\text { archetype building } \\
\text { models }\end{array}$ \\
\hline Anderson [20] & $\begin{array}{l}\text { UK TUS } 1985 \text { and } \\
2005\end{array}$ & $\begin{array}{l}4,854 \text { individuals } \\
(2005)^{*}\end{array}$ & $\begin{array}{l}15 \text { minutes }(1985) \text {, each } \\
\text { day of a selected week, } \\
10 \text { minutes }(2005,1 \\
\text { diary day) }\end{array}$ & $\begin{array}{l}\text { Analysis of laundry } \\
\text { activities and related } \\
\text { energy demand }\end{array}$ \\
\hline
\end{tabular}

*datasets refer to subsamples of the TUS used in the studies

\section{DATA AND METHODOLOGY}

\subsection{The Danish Time Use Survey (TUS)}

\subsubsection{Framework}

The occupant behaviour and activity profiling presented in this study was based on the Danish TUS 2008/2009. In particular, it relied on responses from 9,640 individuals from 4,679 households drawn randomly from a part of the Danish population aged 18-74 years [33]. The Danish TUS included three tools for data collection from the population: a questionnaire, a diary and an expenditure booklet (Figure 1).

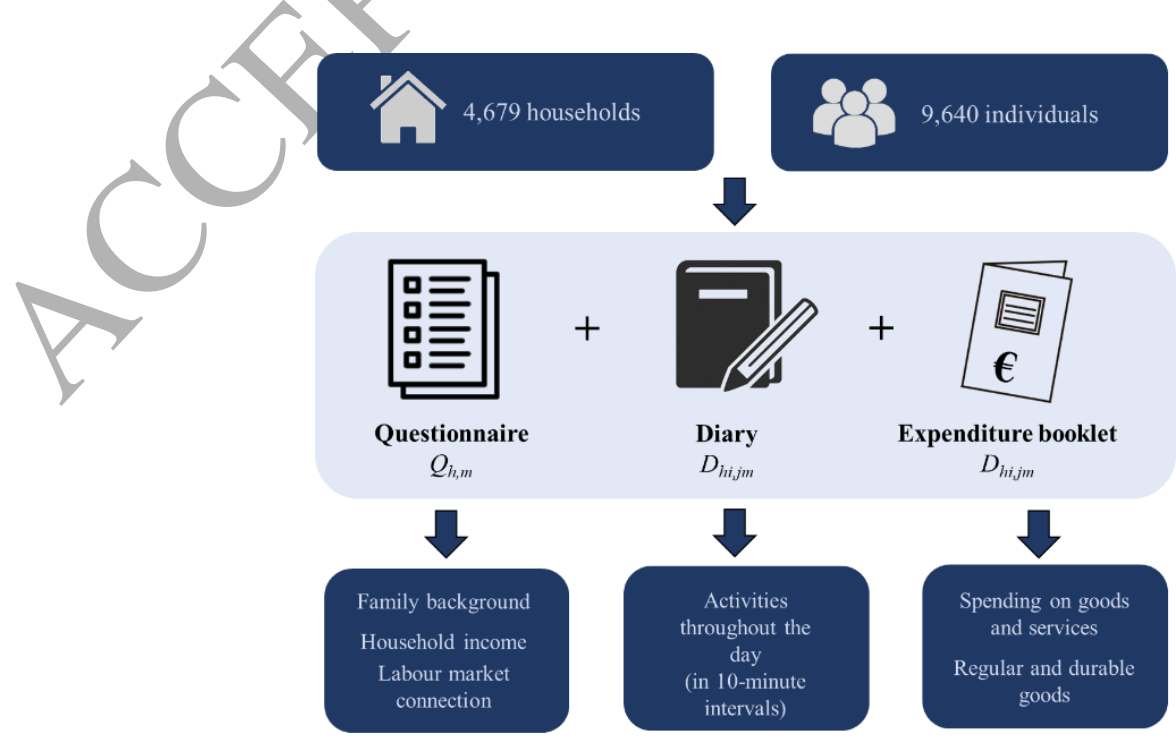


Figure 1. The Danish TUS framework. h represents the household, $i$ the individuals/household members, $j$ the diary day - weekday or weekend day - and m the method used-telephone or web.

As explained by Bonke [33], the questionnaire consisted of 50 questions soliciting general information on the respondents such as family background, incomes, and labour market connection. Furthermore, respondents were asked to complete two forms for daily time use - one for a specific weekday and one for a specific weekend day. All respondents in the 18-74 age group and, if applicable, their spouse or cohabiting partner and/or children aged 12-17, were asked to complete these time use forms. The main respondent of the family completed surveys for children under 12 .

A pre-coding system for different types of activities was provided in the diary for enabling the respondents to easily compile the TUS and to facilitate data analysis. The day was divided into 10-minuteintervals, 144 in total. The time spent on a given activity in the course of a day therefore becomes the sum of 10 -minute increments, where these activities occur. This was intended to ensure more consistent processing of the responses. Interviews were conducted at regular intervals over twelve months, covering the period of March 2008 to March 2009. A detailed description of the survey can be found in [34] and Bonke and Fallesen [35] where detailed response rates ( $48 \%$ for the diary) and other information are specified,

\subsubsection{Representativeness of the Danish TUS}

The authors provide a more detailed description of the main characteristics of the respondents in order to establish if the background information on respondents of the Danish TUS was comparable to national statistics. This pre-analysis was hence aimed at excluding significant sampling errors of the TUS sample with respect to the entire Danish population. In detail, the background information of the respondents collected in the questionnaire (Danish TUS 2008/09) was compared to the same type of statistical data available for research at the national level [36] in 2008 (DK-2008) and 2015 (DK-2015). These two years were chosen for the comparison in order to provide a reference during the year in which the survey was compiled (2008) and to investigate whether the trend significantly changed in recent times (2015). In general, the age distribution of the respondents and the Danish population had a similar trend with a slight overrepresentation of 41-60 years old respondents (Figure 2a). Both amongst the respondents and in the Danish population, one- and two-member households were the most frequent, while a smaller fraction lived in households of three to six people (Figure 2b). There was a balanced gender ratio of $51 \%$ male to $49 \%$ female among the respondents.

The trend in the surveyed yearly household net income (DKK) was slightly smoother than the trend of DK2008, which clearly peaked at incomes lower than 200.000 DKK (Figure 2c). Nevertheless, the trends were comparable and the Danish TUS can be considered representative for the Danish population. In general, the highest percentage of the respondents were employees (27\%) and students (16\%). Both retired survey respondents and skilled workers represented $10 \%$ of the total respondents; all the other categories represented a lower percentage of the total sample size. More information on work statuses of the survey respondents can be found in [37]. 


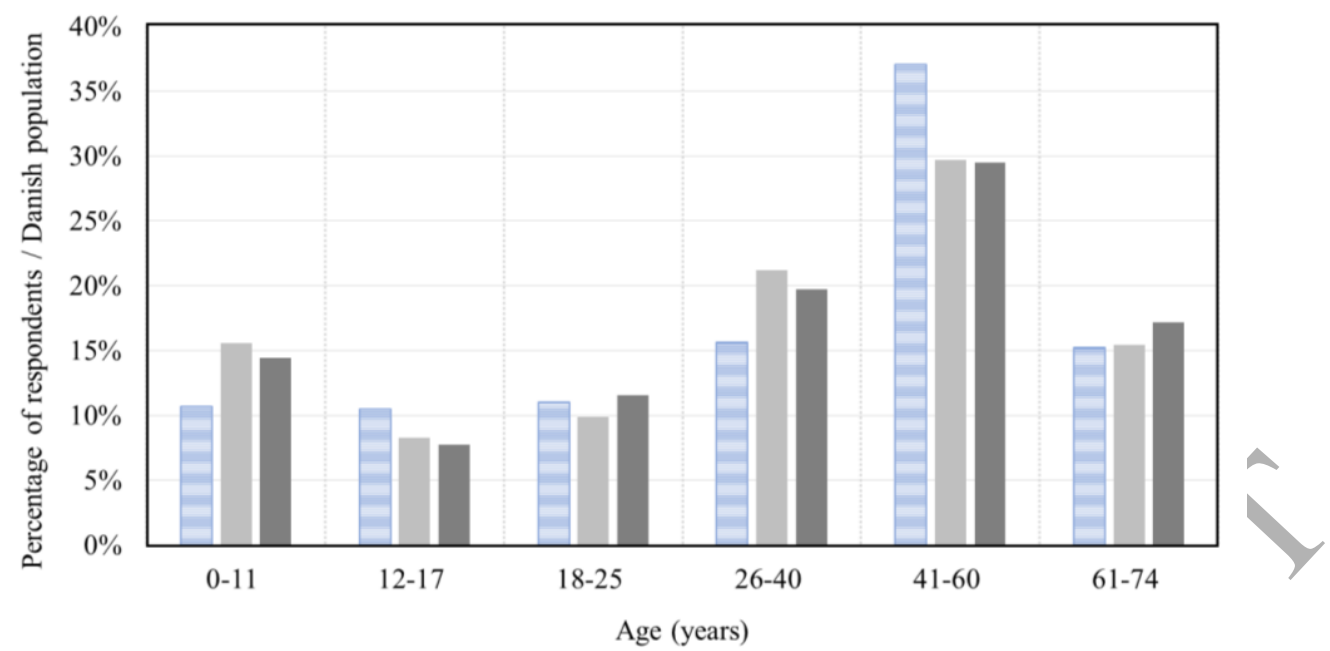

(a)

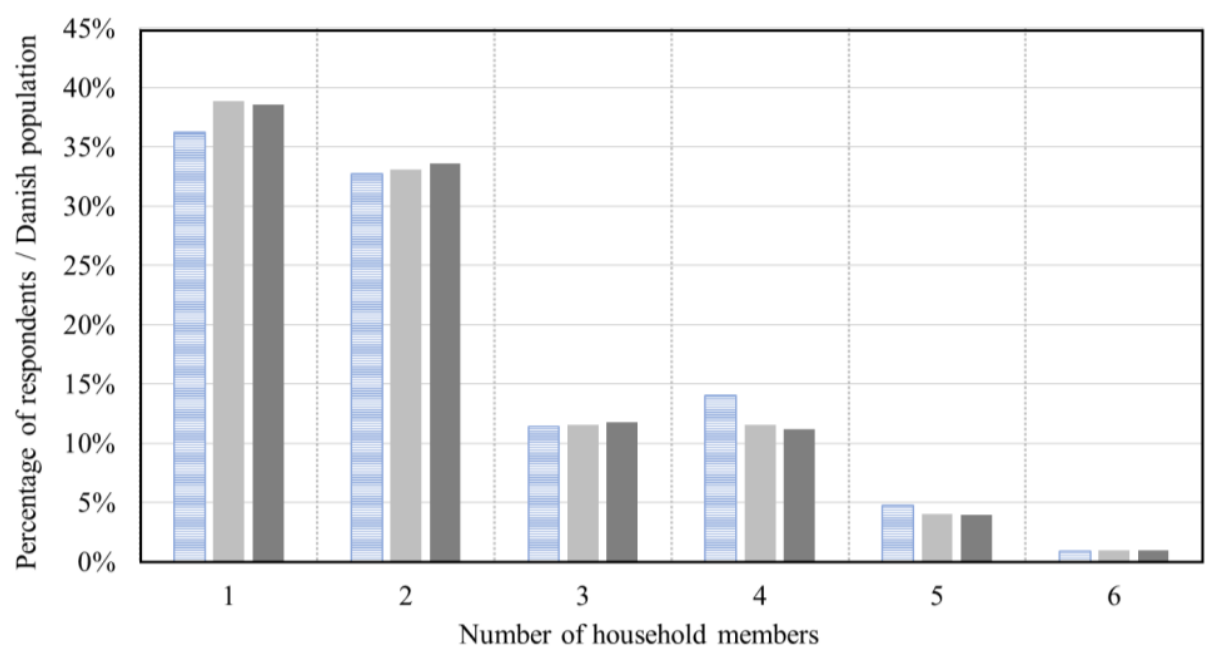

(b)

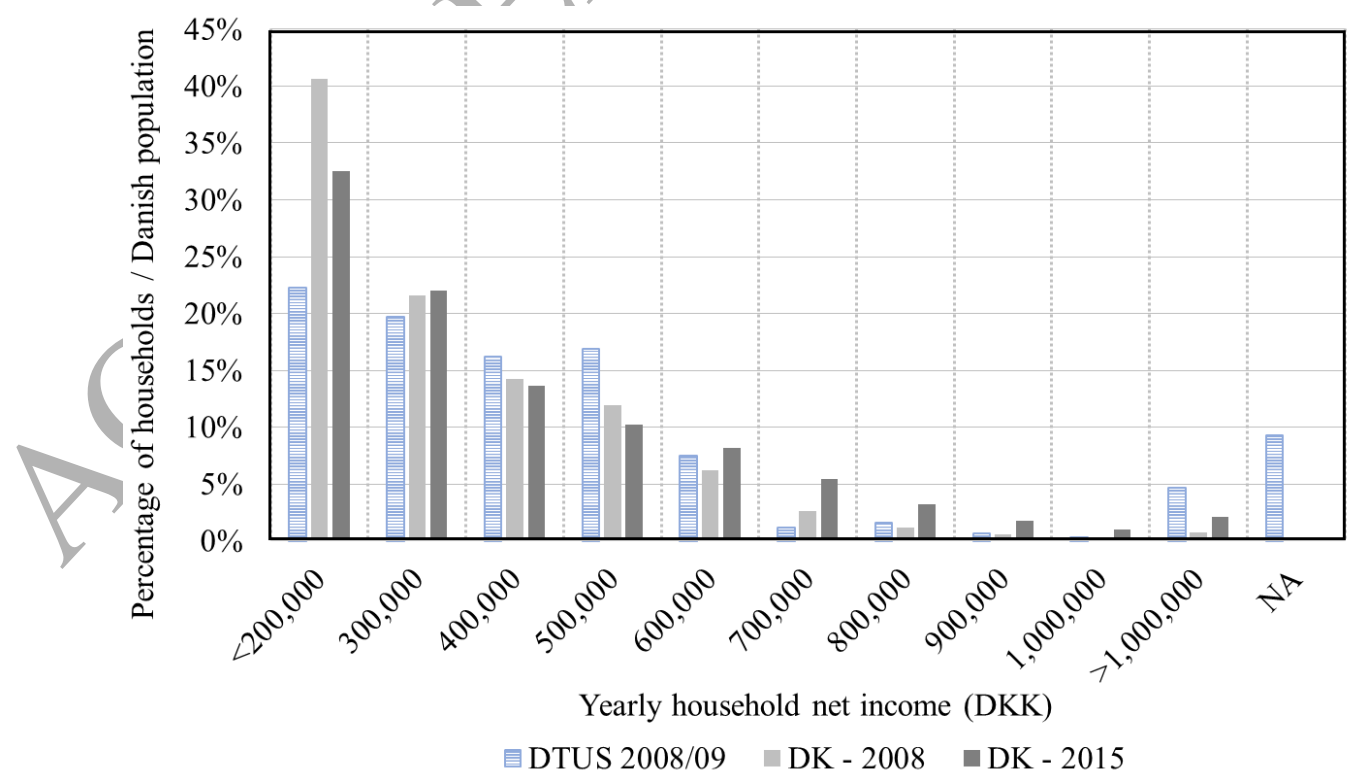

(c)

Figure 2. Danish TUS data (2008) and comparison to statistical data on Danish Population (2008 and 2015): (a) Age, (b) Household composition and (c) Yearly household net income. 


\subsection{Profiling energy-related activities (i)}

The Danish TUS framework pre-coded and included over 35 primary activities, which were selected by the respondents for describing in 10-minute intervals how they spent their day. In this study, the activities in the original survey framework were consolidated into a set of 10 energy- and occupancy-related activity clusters valuable for occupant behaviour analysis in the residential sector. The new set of 10 clustered activities is shown in Table 2 [37]. Since the focus of the study was to model occupant behaviour in dwellings, activities taking place outside the domestic environment were all placed in category: no. 9 "not at home". Moreover, the definition of a category "not at home" allowed for development of detailed occupancy profiles (see section 2.4). Based on this updated set of activities, the first step of analysis consisted of shaping daily activity profiles of the building occupants throughout the day.

Table 2. Activity clustering

\begin{tabular}{lll}
\hline No. & New clusters & Activities included in the Danish TUS 2008/09 \\
\hline $\mathbf{1}$ & Sleeping & Sleeping \\
\hline $\mathbf{2}$ & Toilette & Toilette \\
\hline $\mathbf{3}$ & Eating & Eating \\
\hline $\mathbf{4}$ & Cooking/Washing dishes & Cooking/Washing dishes \\
$\mathbf{5}$ & Cleaning/Washing clothes & Cleaning/Washing clothés \\
\hline $\mathbf{6}$ & Practical Work & Other work, do-it-yourself work, garden work \\
\hline $\mathbf{7}$ & Family care/Free time & Child care, reading with children, family care, reading, hobby, social \\
& & gathering, phone conversations \\
\hline $\mathbf{8}$ & Relaxing/TV/IT & TV/radio/music, IT, rélaxing \\
\hline $\mathbf{9}$ & Not at home & Work, lunch break, transportation as part of work, transport to and \\
& & from work education, education, transport to and from education, \\
& & shopping, errands, visiting public offices, pick up/bring children, \\
& & association activities, voluntary work and similar, exercise/sport, \\
& & entertainment/culture, restaurant/café \\
\hline $\mathbf{1 0}$ & Others & Others \\
\hline
\end{tabular}

\subsection{Investigation on time-related factors (ii)}

\subsubsection{Distribution of activity durations}

This analysis was/aimed at understanding typical durations of the identified activities throughout the day. The Kaplan-Meier estimate, which is a non-parametric method for describing the fraction of activities persisting for a certain amount of time [38]. The Kaplan-Meier estimate [39] involves computing probabilities of occurrence of event after a certain amount of time. To create a survival curve that yielded the time durations of the activities, we calculated the survival probability for each activity according to Equation 1:

$$
S\left(t_{i}\right)=\prod_{i=1}^{N}\left(1-\frac{d_{i}}{n_{i}}\right)
$$


where $S\left(t_{i}\right)$ is the probability of survival at time $t_{i}, d_{i}$ is the number of ceased activities at time $t_{i}$ and $n_{i}$ the number of continued (surviving) activities at time $t_{i,}$.

\subsubsection{Transition states}

A further analysis outlined the starting and ending times of the activities during weekdays and weekends. For this, transition states (activity started, activity ended) were defined for eight activities and then accumulated on an hourly basis. Table 3 shows an example of transition states for activity 3 . In this case, a survey respondent performed activity 3 for half an hour; the starting and the ending time of this activity were described by the transition states "activity started" and "activity ended", respectively. Activity 9 ("not at home") was analysed separately in section 2.5 regarding the definition of occupancy profiles and activity 10 ("others") was not considered relevant for the analysis.

Table 3. Transitions states of activity 3

\begin{tabular}{cccc}
\hline Time & $\begin{array}{c}\text { Activity state (survey } \\
\text { response) }\end{array}$ & $\begin{array}{c}\text { Transition state "activity } \\
\text { started" }\end{array}$ & $\begin{array}{c}\text { Transition state "activity } \\
\text { ended" }\end{array}$ \\
\hline $\mathbf{0 0 : 0 0}$ & 0 & 0 & 0 \\
\hline $\mathbf{0 0 : 1 0}$ & 3 & 1 & 0 \\
\hline $\mathbf{0 0 : 2 0}$ & 3 & 0 & 0 \\
\hline $\mathbf{0 0 : 3 0}$ & 3 & 0 & 0 \\
\hline $\mathbf{0 0 : 4 0}$ & 0 & 0 & 1 \\
\hline $\mathbf{0 0 : 5 0}$ & 0 & 0 & 0 \\
\hline
\end{tabular}

\subsection{Occupancy patterns (iii)}

The definition of representative occupancy profiles for the Danish residential sector during weekdays and weekends was addressed by analysis of the clustered activity 9 ("not at home"). Activity 9 provided information on when occupants were absent from home, while all the other activities took place in the domestic environment. A departure event occurred when activity 9 was started and a returning event occurred when activity 9 ended. In detail, activity 9 included activities performed outside the house.

The probability of leaving home $(\mathrm{LH})$ and returning home $(\mathrm{RH})$ in the next hour at a given time of day $n$ was calculated according to Equations 2 and 3, respectively:

$$
\begin{aligned}
& P(L H)(n)=\frac{\text { Number of departure events at time step } n}{\text { Number of respondents at home at time step } n-1} \\
& P(R H)(n)=\frac{\text { Number of returning events at time step } n}{\text { Number of respondents away from home at time step n-1 }}
\end{aligned}
$$

\section{RESULTS}

\subsection{Shaping daily activity profiles (i)}


Figure 3 shows the percentage of respondents carrying out each of the ten identified activities throughout the day. Sleeping was clearly the dominant late evening - early morning activity with $90 \%$ of the survey respondents being asleep between 00:40 and 06:00. There were two evident peaks in "eating", corresponding to lunchtime (ca.12:30) and, dinnertime (ca. 18:30). Two other large portions of the graph represent the activities "Not at home" (Activity 9) and "Relaxing/TV/IT" (Activity 8). The largest percentage of survey respondents were out of home around 11:20 and returned during the afternoon hours. A large percentage of respondents were at home during the whole or a large extent of the day. This might be due to the fact that Figure 3 was based on the same number of weekdays and weekend days during which respondents tended to stay home longer (see Figure 4). The full percentage of total respondents at each time step corresponds to 9,518-9,521 respondents for weekdays and from 9,607 to 9,640 respondents for weekends. As regards the activity related to relaxing and the use of TV and IT devices, a peak can be observed between 19:00 (after dinnertime) and 23:00. In particular, the identified patterns related to (a) cooking/washing dishes, (b) occupancy (at home/not at home) and (c) use of TV and IT devices provided valuable energy-related information with respect to occupant behaviour and its impact on building energy use.

It is important to highlight that Figure 3 combined all of the collected survey responses in one graph, without distinguishing activities with respect to different seasons of the year or different days of the week. Figure 4 compared the daily activity profiles during different seasons and on weekdays (WD) and weekends (WE). No noticeable differences were found respectively between the spring/autumn and the summer/winter period. As a consequence, Figure 4 only shows outcomes related to summer (June, July and August) and wintertime (November, December and January).

The key results of this analysis were:

- longer sleeping times during weekends $(8 \mathrm{~h} 39 \mathrm{~m}-9 \mathrm{~h} 1 \mathrm{~m})$ with respect to weekdays $(8 \mathrm{~h}-8 \mathrm{~h} 17 \mathrm{~m})$;

- longer sleeping times in winter than in summer on both weekdays ( $8 \mathrm{~h} 17$ and $8 \mathrm{~h}$, respectively) and weekends ( $9 \mathrm{~h} 1 \mathrm{~m}$ and $8 \mathrm{~h} 39 \mathrm{~m}$, respectively);

- more time spent on practical and garden work in summer $(43 \mathrm{~m}-1 \mathrm{~h})$ than in winter $(19-22 \mathrm{~m})$;

- more time spent out of home during weekdays (6h30m-6h41m) than on weekends $(3 \mathrm{~h} 51 \mathrm{~m}-4 \mathrm{~h} 9 \mathrm{~m})$;

- longer relaxing times on weekends (3h59m-4h14m) than on weekdays (3h6m-3h32m);

- small difference in time spent for toilette (ca.40m) and cooking/ washing (ca.40m) for different seasons and/or day types;

- in broad-ranging activities, such as "not at home", "others" or "relaxing/free time", the values of standard deviation indicated high variability and spread of the data due to occupant diversity - while more specific activities, such as sleeping, eating or toilette were characterised by a lower variability among occupants.

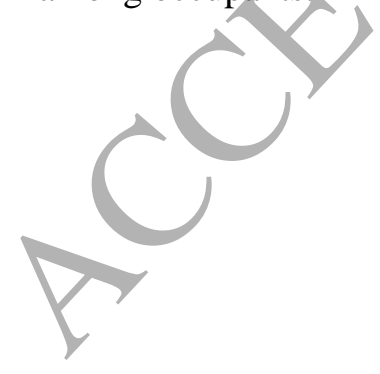




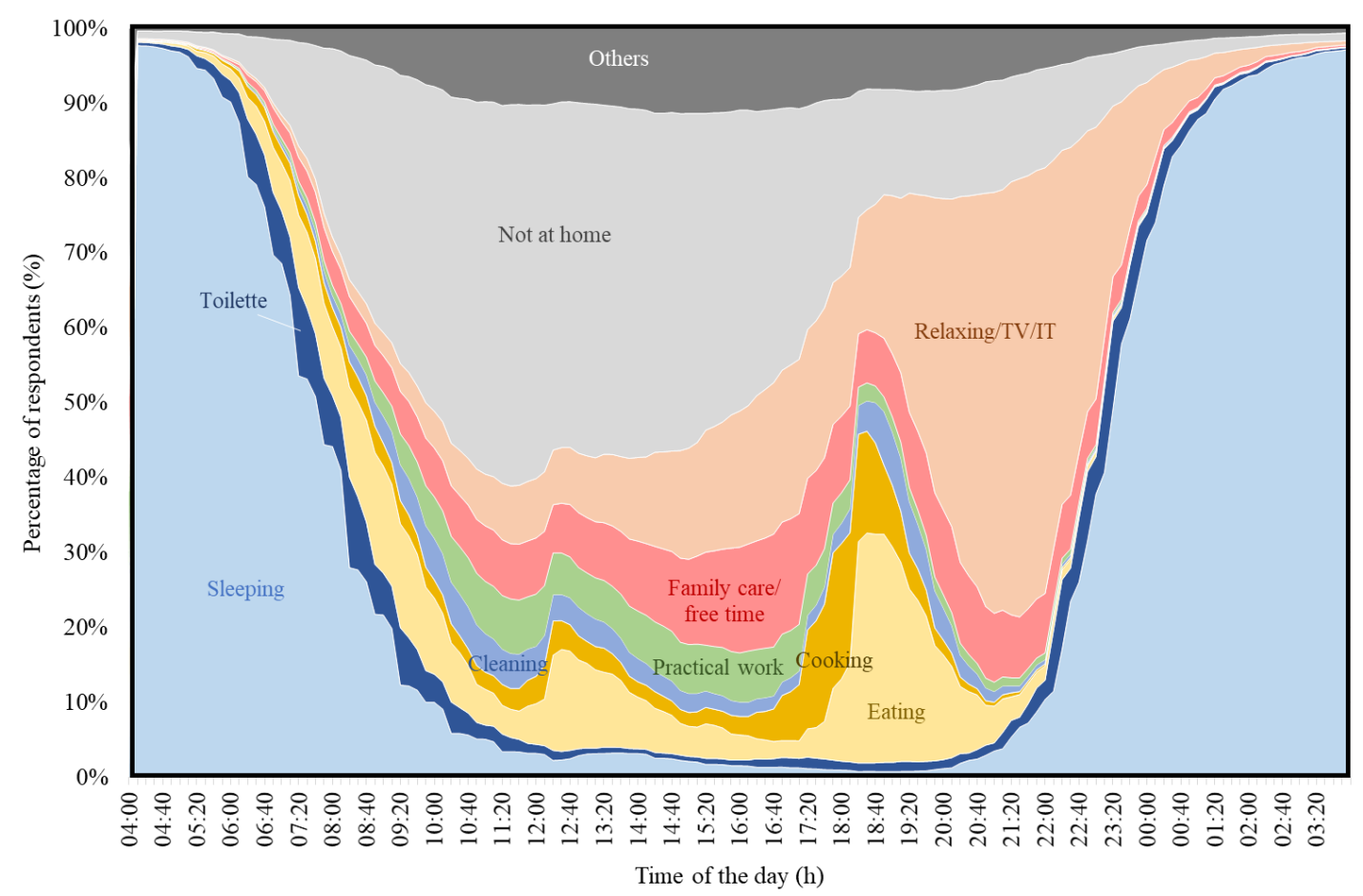

Figure 3. Daily activity profiles based on DTUS 2008/2009 (all days).

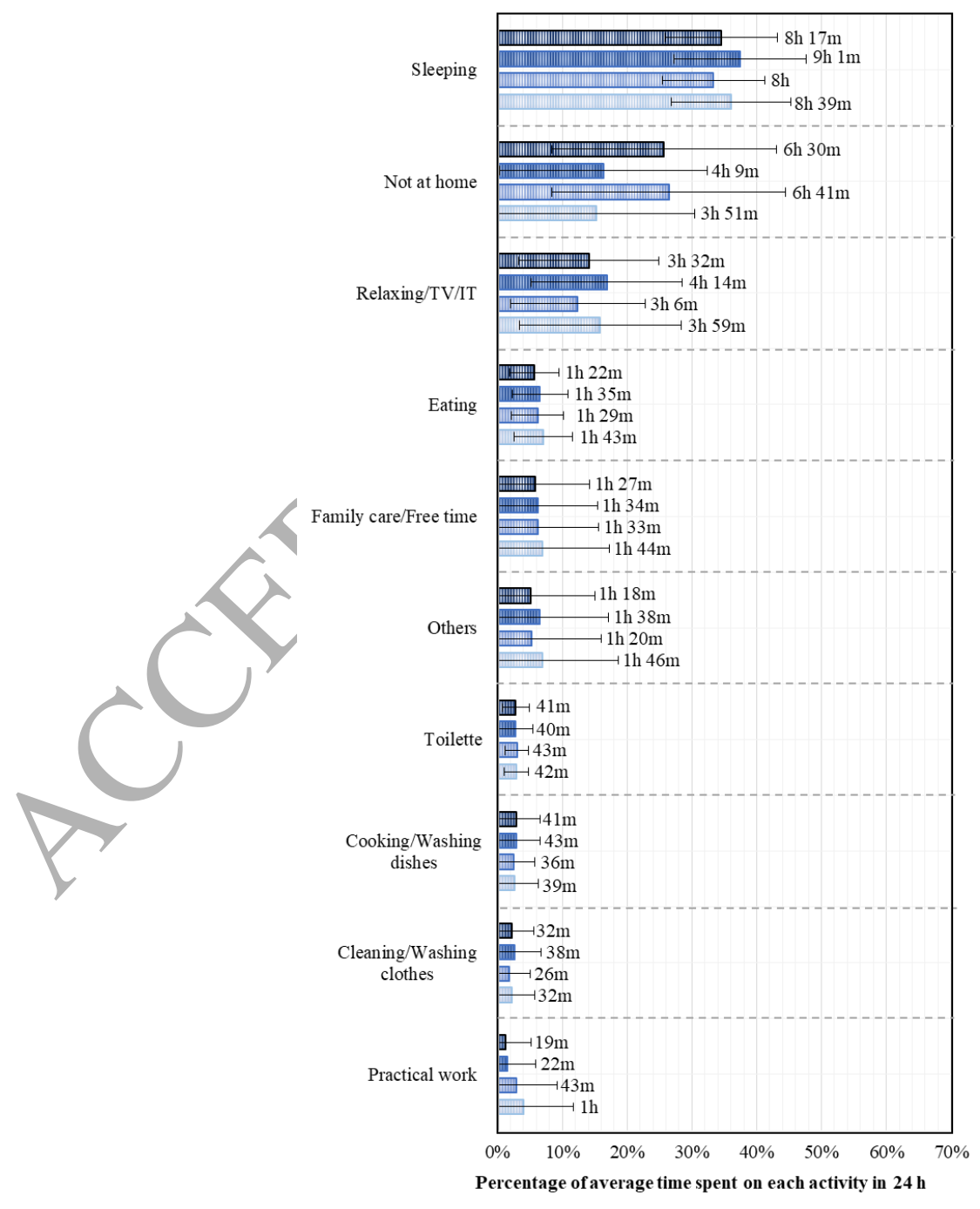

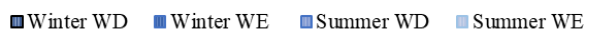


Figure 4. Daily time spent on the activities during summer and winter weekdays/weekends ( \pm 1 St.Dev.).

\subsection{Time-related factors: Time durations and starting/ending times (ii)}

\subsubsection{Survival curves of activities' daily time durations}

Figure 5 shows the probability that an activity survives for longer than a given period $t$ once it has started. The longest time durations were linked to the sleeping activity. Around $90 \%$ of the respondents slept at least six hours in a row and 10\% slept longer than 10 hours in a row. The second longest daily time durations were linked to activities away from home ("not at home"), this survival curve was less steep than the others, which reflected the large variety in duration of this activity throughout the day. The second longest activity performed at home, after sleeping, was relaxing and TV/IT usage. The activities with shortest durations were toilette, cooking/washing dishes, cleaning/washing clothes, and eating.

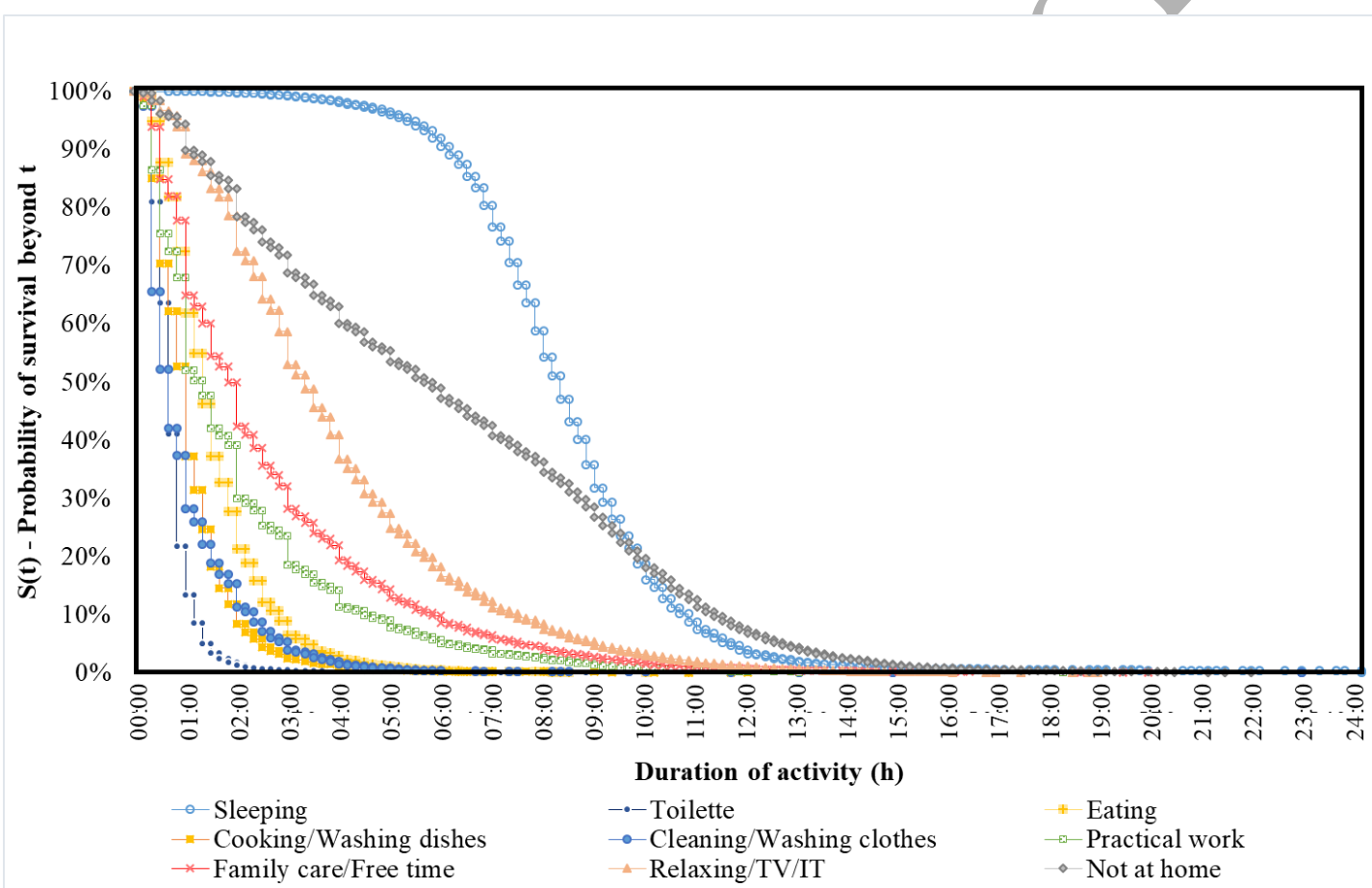

\subsubsection{Starting/ending times of activities}

The number of activities started throughout the day is shown on an hourly basis in Figures $6 \mathrm{a}$ and $6 \mathrm{~b}$ for a typical weekday and weekend day, respectively. Figure 7 depicts when the same activities ended on a typical weekday (Figure 7a) and weekend day (Figure 7b). These graphs provided insights into the time dependency of the activities and highlighted the following key aspects:

- generally, there were three peak times for initiation of activities: morning hours (07:00-09:00), the late afternoon/early evening hours (18:00-20:00) and at bedtime (23:00); 
- most survey respondents started their sleeping activity between 22:00 and 00:00 and ceased the activity between 06:00 and 10:00; moreover, both the onset and termination of sleeping activity was shifted later during weekend days;

- There were clear peak values for toilette use in the morning and evening hours in correspondence of the starting and ending time of the sleeping activity;

- as expected, the highest number of eating activities started and ended during breakfast (07:00-10:00), lunch (12:00-14:00) and dinnertime (18:00-20:00); cooking and washing dishes were also linked to these starting and ending times;

- activities related to relaxing and TV/IT usage began during the afternoon hours and reached the highest number of started activities in the evening hours (19:00-21:00); these activities mostly ended during the late evening hours (21:00-01:00);

- activities related to practical work and family care were not dependent on time of the day and starting/ending times were equally distributed throughout different hours of the day.

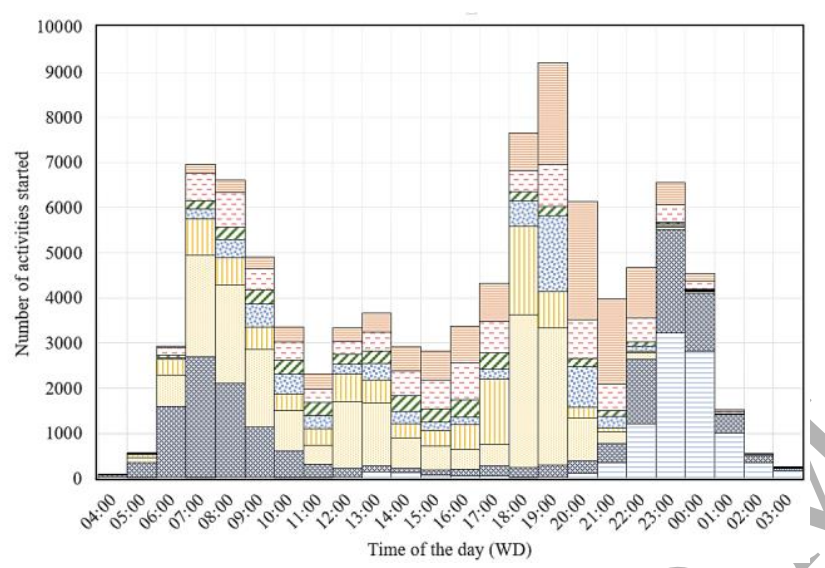

(a)

$\square$ Sleeping

$\square$ Cooking/washing dishes

$\boxminus$ Family care/free time

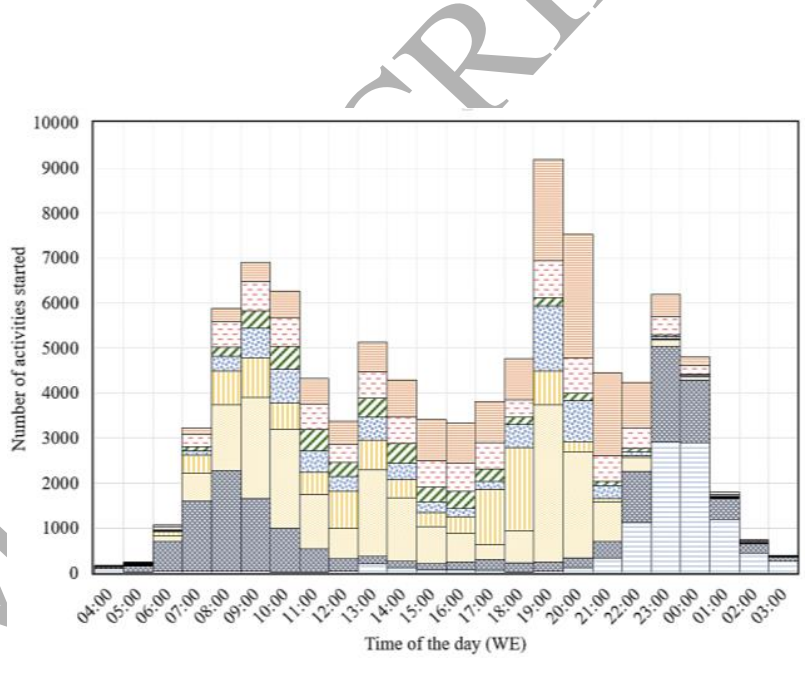

(b)

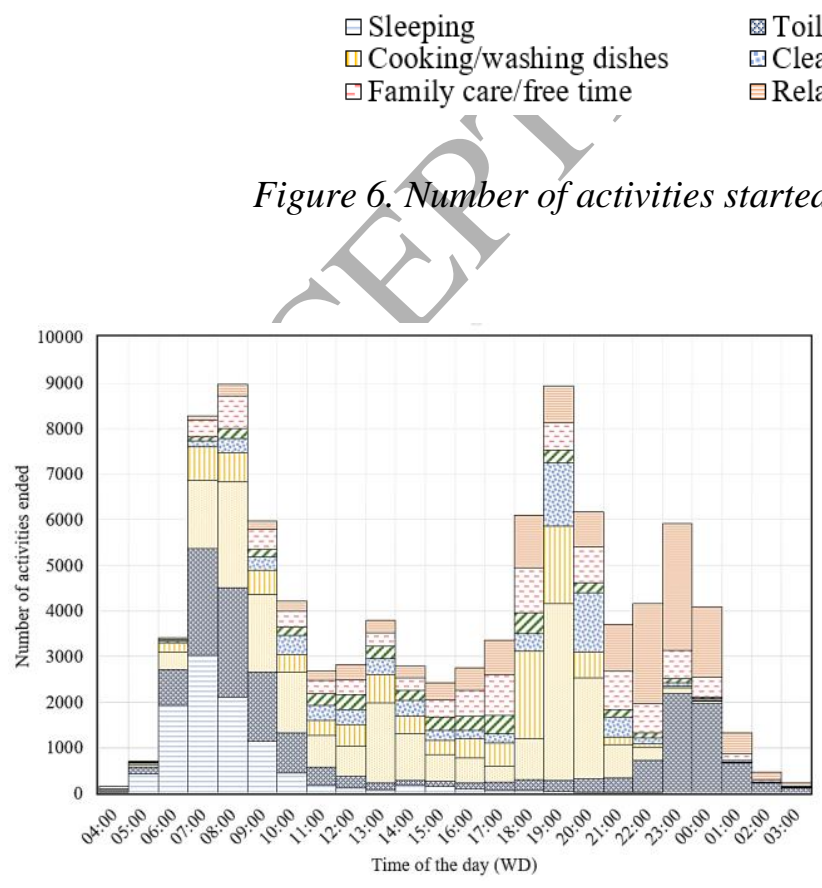

(a)

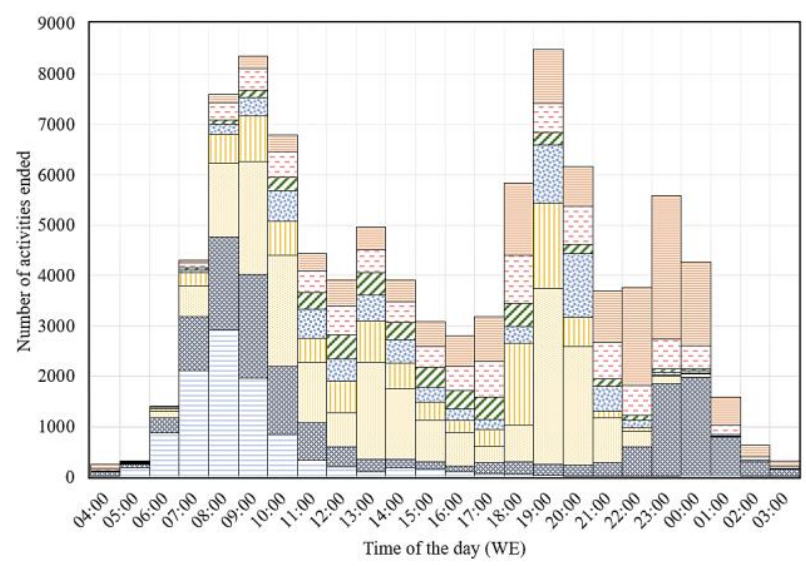

(b) 
$\square$ Sleeping

$\square$ Cooking/washing dishes

$\square$ Family care/free time

\author{
图 Toilette \\ Cleaning/washing clothes \\ $\boxminus$ Relaxing/TV/IT
}

$\square$ Eating

$\square$ Practical work

Figure 7. Number of activities ended during (a) weekdays and (b) weekends.

\subsection{Occupancy profiling (iii)}

The aim of this section is to gain a deeper knowledge on occupancy patterns in Danish households and to describe probabilities of occupancy related to state (probability of number of respondents at home) and transitions (probability of leaving/returning home). This information can be further elaborated for developing stochastic models aimed at capturing more accurately human presence in BEPS, and consequently contribute to reducing the gap between predicted and measured energy consumptions in the building sector. Figure 8 depicts the percentage of survey respondents at home throughout the day during weekends and weekdays. The highest percentage of respondents not at home occurred in the late morning hours, a small portion returned home at lunchtime, while most of the respondents came home during the late afternoon/evening hours. During the weekend, a larger fraction of the survey respondents were home compared to weekdays. Figure 9 shows occupancy profiles during weekdays and weekends for different sized households. The percentage of survey respondents at home was referenced to the number of household members in each category. For example, in a 2P household $100 \%$ meant that 2 persons were at home and in a 3P household $100 \%$ meant that 3 persons were at home.
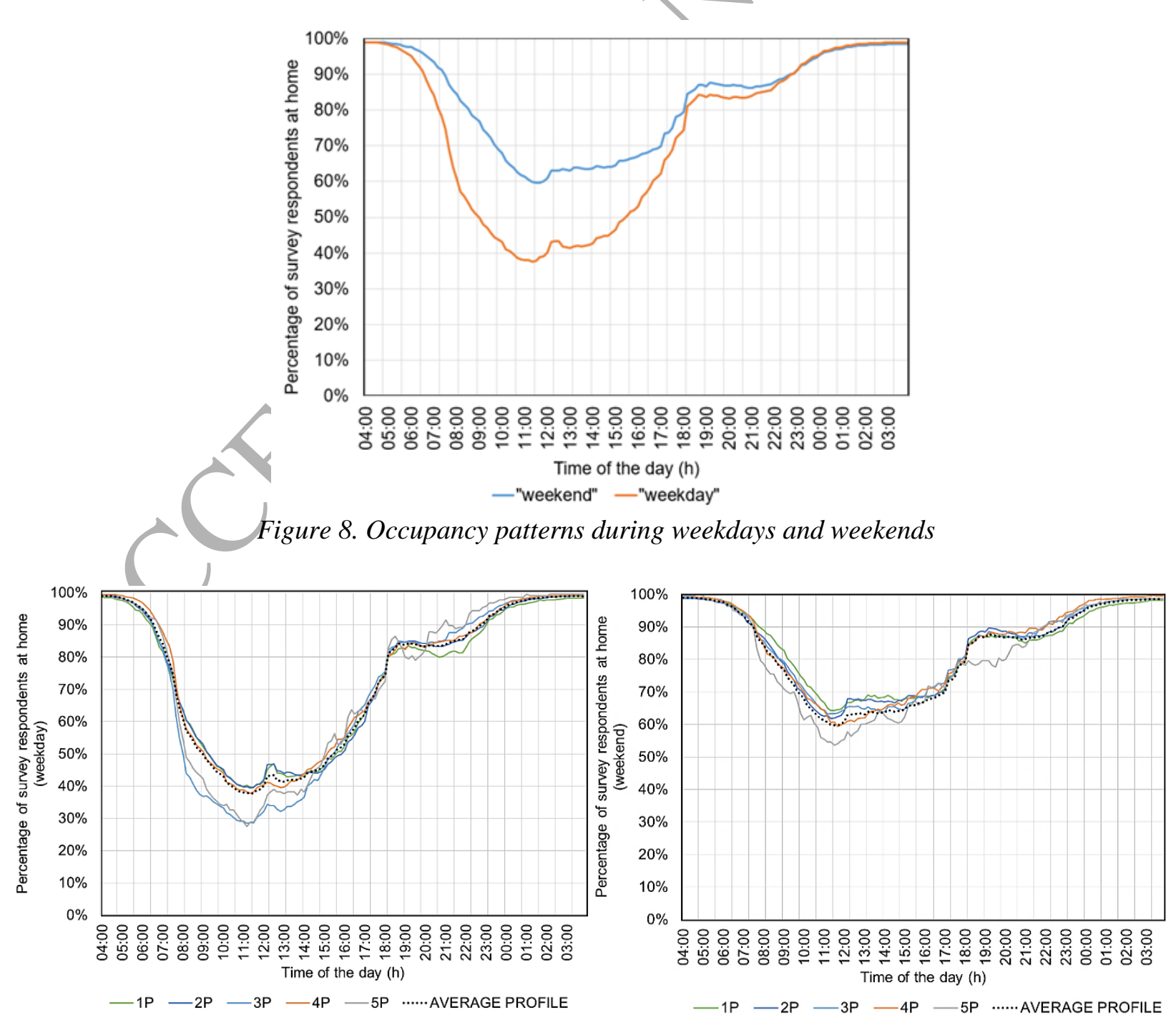
(a)

(b)

Figure 9. Occupancy patterns for different household compositions ( $* P=$ number of household members) during (a) weekdays and (b) weekends.

Figure 10 depicts the probability of leaving (Figure 10a) and returning to the home (Figure 10b) within the next hour during weekdays and weekend days, respectively. The probability of leaving home was highest in the morning (06:00-08:00) and early afternoon hours (12:00-13:00). The probability of returning home was highest during lunchtime (11:00-13:00), dinnertime (16:00-18:00) and late evening (22:00-24:00). The probabilities of departure and arrival were calculated as the fraction of the total number of arrival or departure events at a time step and the number of respondents that were at home or away from home in the previous time step, respectively (Equation 2 and 3).

The probability of leaving home is characterised by less evident peak values during weekends than during weekdays (Figure 10a), while there were less difference in the peaks for the returning hours during weekdays and weekends (Figure 10b). Aggregated hourly data was used for this analysis to overcome inconsistencies in data trends at higher time resolutions (10-minute intervals) due to the tendency of survey respondents' to report the start or the end of activities at the full hour or half hour.

The levels of occupation were further analysed for different household types with different numbers of household members (from single-person households to 4-person households), and different types of day. To gain a better overview, a spectrum of occupancy profiles shows the level of occupation in 150 randomlychosen households for each household type during weekdays (Figure 11a) and weekends (Figure 11b). This analysis clearly highlighted a higher occupant density and a more irregular spectrum during weekends with respect to weekdays. The tendency of respondents to leave home earlier during weekdays than on weekends is also clearly readable in the spectrums. A growing density of occupancy can be observed with an increasing number of household members. This analysis allowed for profiling individual occupancy patterns based on household type and day type, which can be directly implemented in BEPS by interested researchers or professionals. To facilitate the applicability of the outcomes of this study in building energy simulation programs, individual occupancy profiles for different household compositions and types of day (weekday/weekend) have been made freely available online:

(http://www.ib.byg.dtu.dk/english/Research/research_groups/Human_Performance_and_behaviour/DanishResidential-occupancy-profiles).

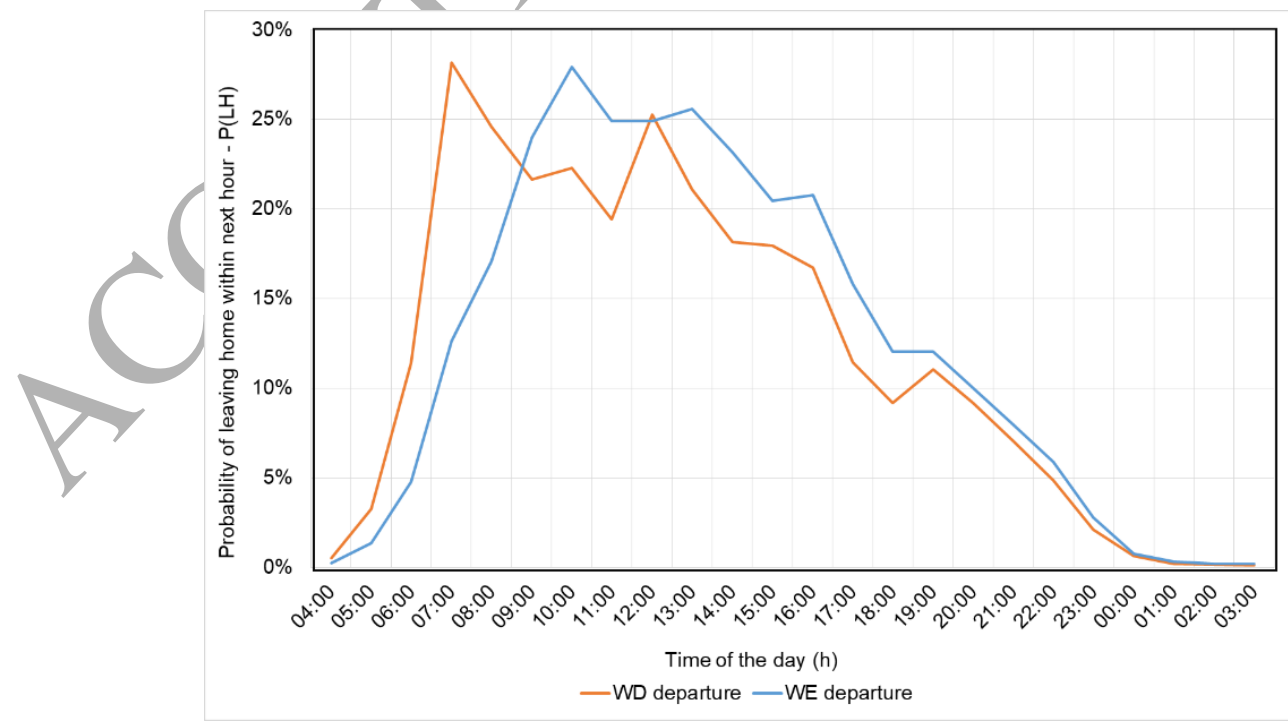

(a) 


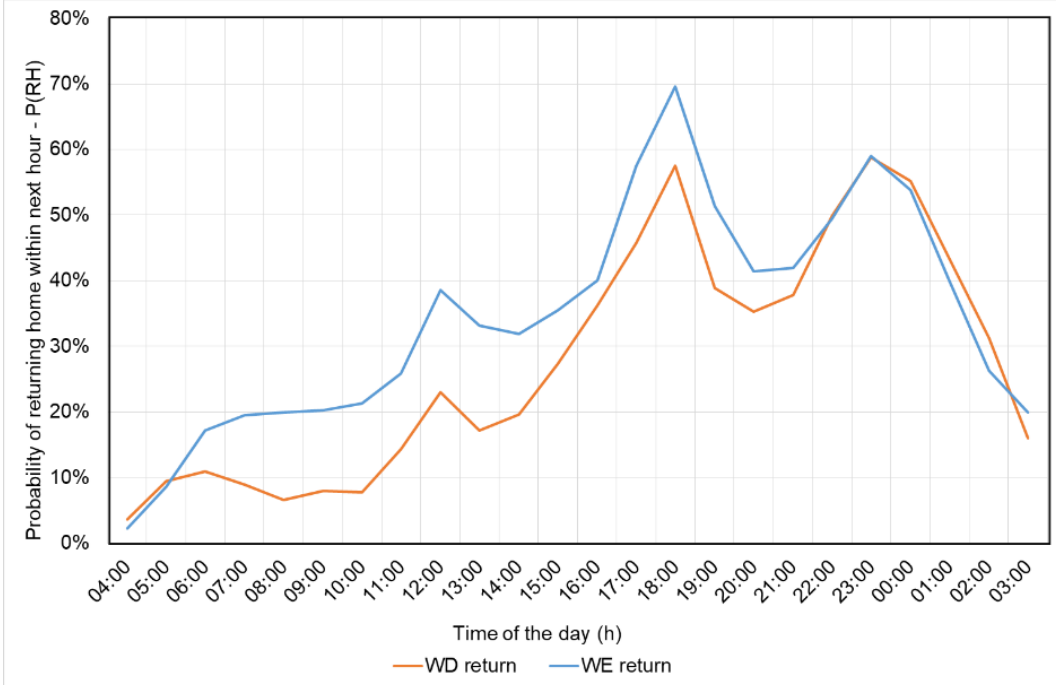

(b)

Figure 10. Probability of (a) leaving home and (b) returning home during weekdays and weekends.

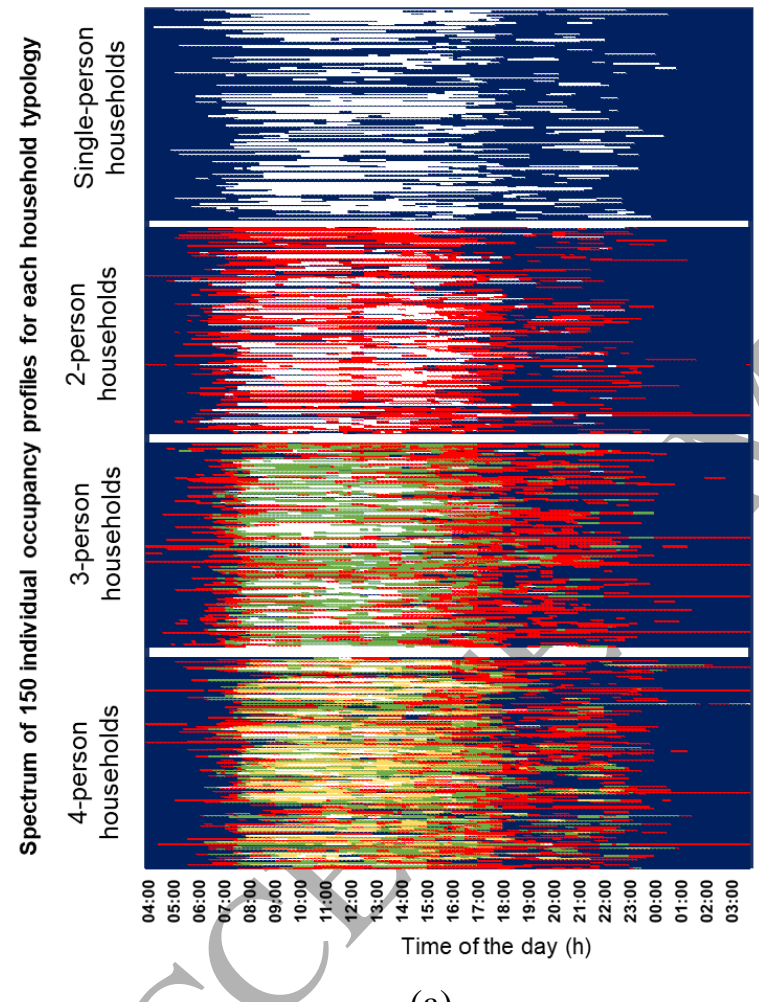

(a)

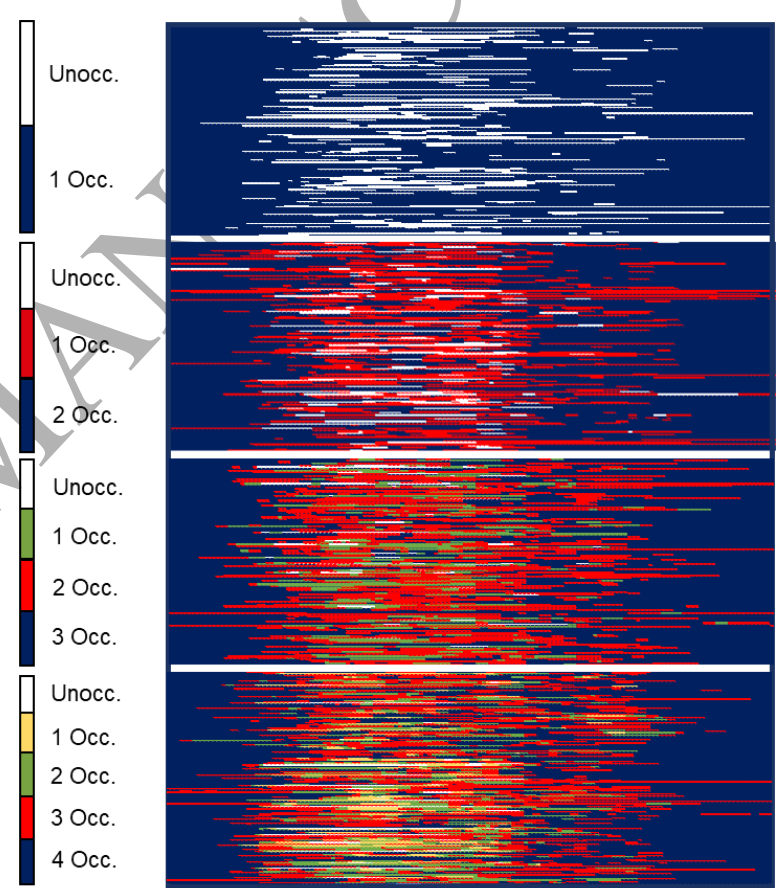

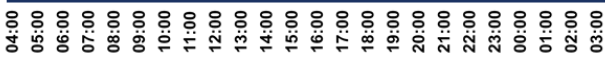
Time of the day $(\mathrm{h})$

(b)

Figure 11. Spectrum of 150 randomly-chosen individual occupancy profiles of different household typologies (single-person households to 4-person households) during (a) weekdays and (b) weekends. The occupation level is defined by number of occupants (occ.) at home.

\section{DISCUSSION}

The survey respondents and background information (with respect to, e.g., household composition, age range, yearly net income) of those who completed the DTUS 2008/2009 can be considered representative of the Danish population. To evaluate the applicability of TUS data for modelling occupant behaviour and related energy consumptions, it was necessary to determine whether the created activity profiles can be related to existing studies on electricity use trends in the residential sector. In line with this, the following 
supplementary analysis compared Activity 4 "cooking/washing dishes" (Fig.12), to typical hourly mean electric load profiles in Danish households during weekdays and weekends. The latter refers to the study of Marszal-Pomianowska et al. [40] who developed a high-resolution model of household electricity use based upon a combination of measured and statistical data. Their study shows that typically there are two peaks during weekdays: a morning peak, which is caused by activities such as preparation of breakfast, morning toilette e.g. hair drying, and an evening peak, which reflects dinner preparation/cooking and evening entertainment, e.g. use of TV and/or PC. Furthermore, during weekends, the morning peak often moves to later morning hours due to longer sleep, and it is more flat. As depicted in Figure 12, similar trends was found from the analysis of the DTUS 2008/2009. These outcomes therefore confirmed that these activities could be related directly to the electricity loads in the households with an evident peak during dinnertime. For further comparisons, such as Activity 3 "eating" and profiles from literature the authors refer the reader to [41].

As mentioned previously, the definition of accurate occupancy profiles and their implementation in BEPS is crucial in order to predict building energy use more reliably. Developers of such tools tend to provide fixed predefined schedules that can be implemented when running simulations for other case studies. The U.S Department of Energy (DOE), for instance, developed reference buildings with predefined schedules for the EnergyPlus software [42], such as schedules for occupancy, lighting use, equipment use, ventilation rates or heating and cooling set-points.

To the best knowledge of the authors, there are no existing studies presenting tailored approaches for modelling the presence of building occupants in Danish households. Therefore, the DTUS-based occupancy profile was compared with the occupancy profile provided by DOE. Figure 13 depicts their proposed occupancy profile for weekdays of a mid-rise apartment house [43], which was compared with the occupancy profile obtained from this study. This graph indicates that there is a resemblance between the DOE occupancy profile and the Danish TUS-based occupancy profile. As a consequence, the DOE profile could be implemented in energy simulation software to establish an approximation of average occupancy in Danish households. In cases where closer representation is needed, the average occupancy profiles from Figure 8 and 9 could be used. The occupancy profiles are freely available online and can be used in cases where average profiles are not adequate and where it is important to represent the diversity in occupancy profiles in Danish households [1].

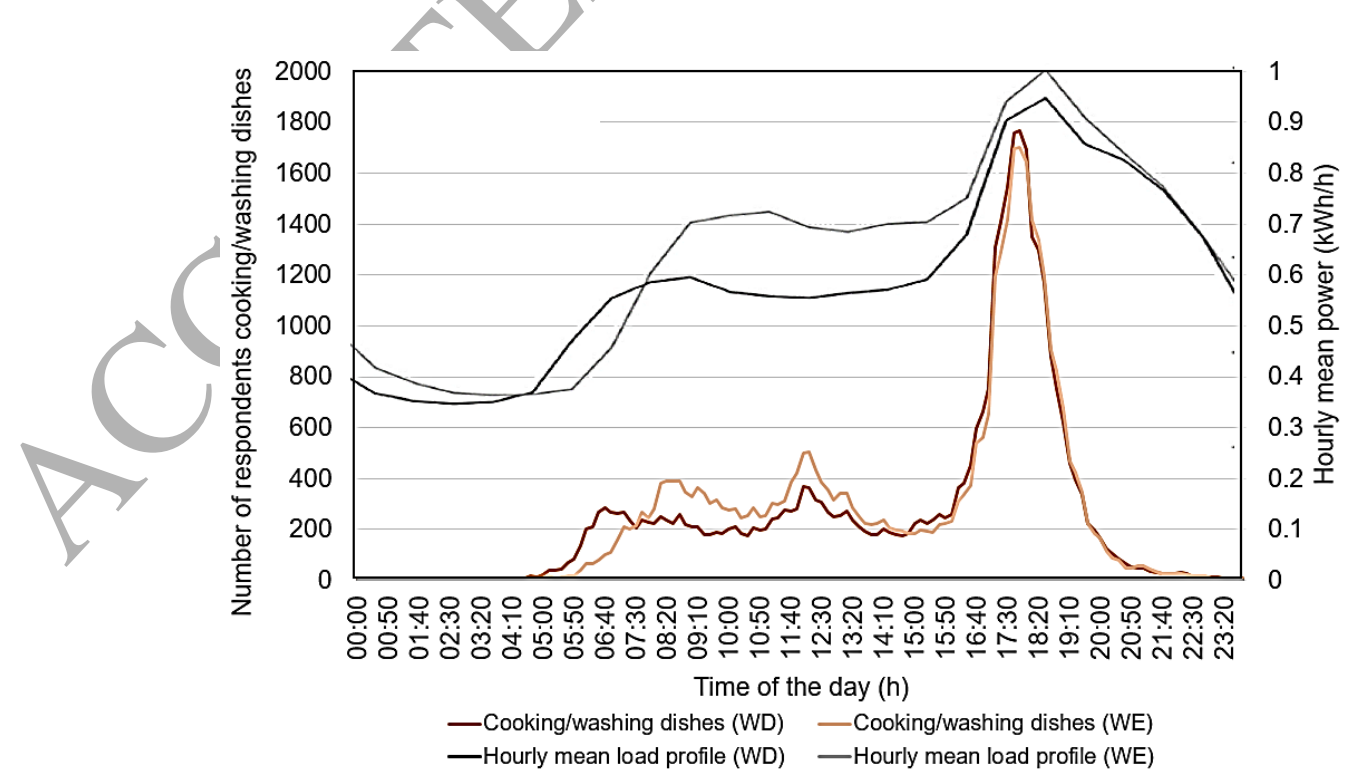

Figure 12. Number of survey respondents cooking/washing dishes during the day compared to hourly mean load profiles. 


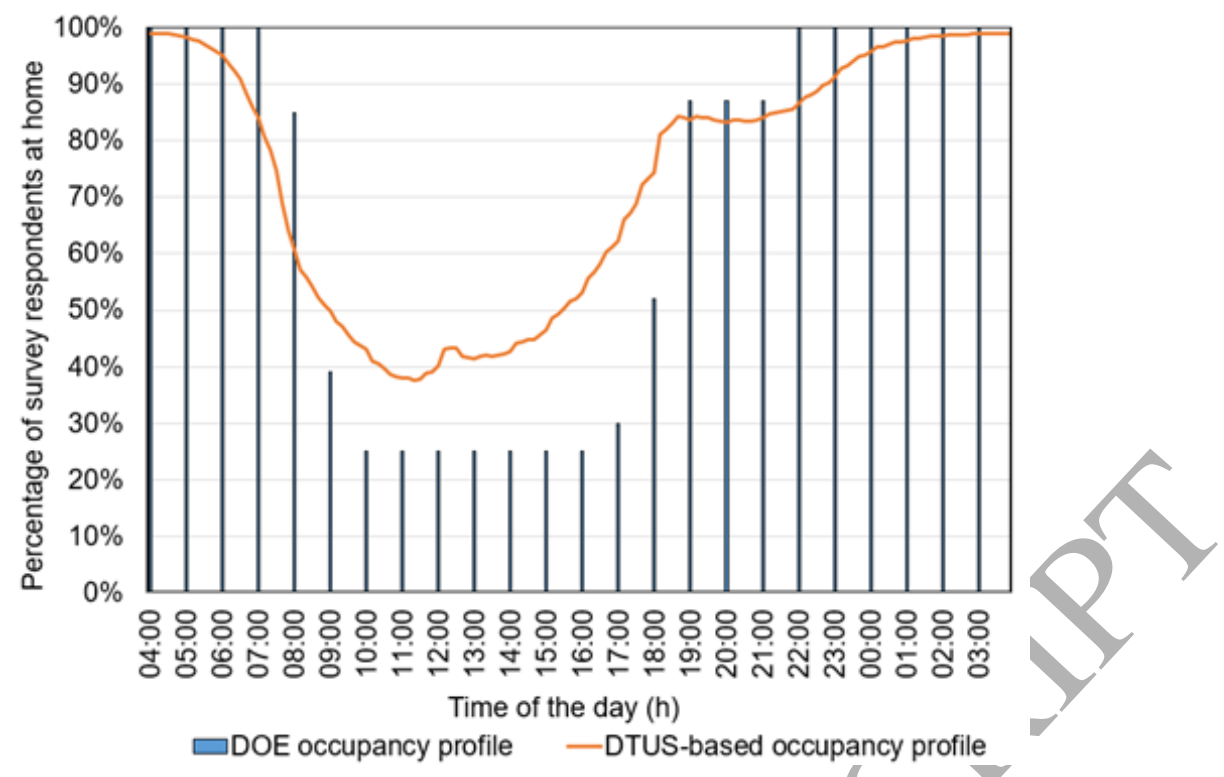

Figure 13. Comparison between the simplified DOE occupancy profile and the DTUS-based week day occupancy profile.

However, it is necessary to acknowledge some limitations related to the application of the Danish TUS data to occupant behaviour profiling and modelling. These limitations are mainly attributable to the fact that most TUS frameworks are not specifically designed for energy-related research purposes. The TUS classification systems may not always reflect meaningful distinctions between specific activities of interest for the desired research task. To obtain a solid conceptual basis for the specific analytic endeavour, it is necessary to extract, transform and/or cluster useful information from the broad-ranging survey framework. The latter includes a large number of activities and sometimes does not allow for an unambiguous interpretation when it comes to the translation of general times use to specific energy-related activities. An important drawback of the Danish TUS framework is that it was not designed to capture simultaneous actions of the respondents (e.g. cooking and watching TV) since they could only report one activity at the time. It is also important to keep in mind that all the data collected in the diary was self-reported: occupants may have underreported or forgot to record some actions or they may have exaggerated the frequency of some of their actions. Respondents also tended to report new activities at the full or the half hour, which to some extent affected the reliability level of resolution of the data analysis when it comes to reporting starting and ending times of the activities. The Danish TUS data available to the authors were analysable only in aggregate form. It was thus not possible to explore other interesting predictors (e.g. job category, age) linked to individual diary entries.

\section{CONCLUSIONS}

The analysis provided in this paper demonstrated that Danish TUS data provides valuable information for developing enhanced building simulation inputs for modelling occupant behaviour and its influence on energy consumption in the Danish residential sector. Daily profiles of ten energy- and occupancy-related activities were different depending on the season day of the week (weekdays and weekends). Survival curves of the daily time durations of the activities provided typical starting/ending times of each activity and representative occupancy profiles for different household typologies during weekdays and weekends. Furthermore, during weekdays occupants were most likely to leave their home at 08:00 or 13:00 and tended to return at noon or in the late afternoon/early evening hours (18:00). To enhance building simulation inputs for occupancy in the Danish residential sector, this paper provided online access to a spectrum of individual occupancy profiles for different household typologies and different days of the week.

The outcomes were in line with typical trends of hourly electricity profiles in Danish households. Indeed, similar peak values of hourly electric load profiles and some energy-related activities were observed during 
the same hours of the day. In detail, these peaks referred to the early morning hours, lunch time and dinner time, and could therefore be strictly correlated to cooking and eating activities. The Danish TUS data provided occupancy patterns similar to an existing simplified occupancy profile developed by the U.S DOE. The Danish TUS is an important source for developing more accurate energy-related occupant behaviour profiles in Danish households. Future work will include further exploration of the TUS data and extracted occupancy patterns to create stochastic models that can be implemented in dynamic energy simulation programs towards bridging the gap between predicted and real energy consumptions. Work is also underway for linking the energy-related activities to the respective electricity demands in order to define high resolution demand profiles in Danish households.

\section{ACKNOWLEDGEMENT}

The authors would like to thank Dr. Jens Bonke and The Rockwool Foundation for providing the Danish TUS data. This research was part of the UserTEC project (User Practices, Technologies and Residential Energy Consumption), which was financed by Innovation Fond Denmark. Rongling Li gratefully acknowledges that her contribution has emanated from research supported by EnergyLab Nordhavn: New Urban Energy Infrastructures and CITIES: Centre for IT-Intelligent Energy Systems in cities.

\section{REFERENCES}

[1] Technical University of Denmark, International Centre for Indoor Environment and Energy, "Danish Residential Occupancy Profiles - Section for Indoor Environment." [Online]. Available: http://www.ib.byg.dtu.dk/english/Research/research_groups/Human_Performance_and_behaviour/DanishResidential-occupancy-profiles. [Accessed: 19-Jul-2018].

[2] Copenhagen Resource Institute, Ecorys, "Resource efficiency in the building sector", Final report on Resource efficiency in the building sector, pp.1-128, (2014). doi:10.1017/CBO9781107415324.004.

[3] C. J. Hopfe and J. L. M. Hensen, "Uncertainty analysis in building performance simulation for design support," Energy Build., vol. 43, no. 10, pp. 2798-2805, 2011.

[4] D. Yan, T. Hong, B. Dong, A. Mahdavi, S. D’Oca, I. Gaetani, and X. Feng, "IEA EBC Annex 66: Definition and simulation of occupant behavior in buildings," Energy Build., vol. 156, pp. 258-270, 2017.

[5] M. Schweiker, "Understanding Occupants' Behaviour for Energy Efficiency in Buildings," Curr. Sustain. Energy Reports, pp. 1-7, 2017.

[6] D. Yan, W. O'Brien, T. Hong, X. Feng, H.B. Gunay, F. Tahmasebi, and A. Mahdavi, "Occupant behavior modeling for building performance simulation: Current state and future challenges," Energy Build., vol. 107, pp. 264-278, 2015.

[7] T. Hong, S. C. Taylor-Lange, S. D’Oca, D. Yan, and S. P. Corgnati, "Advances in research and applications of energy-related occupant behavior in buildings," Energy Build., vol. 116, pp. 694-702, 2016.

[8] I. Gaetani, P. J. Hoes, and J. L. M. Hensen, "Occupant behavior in building energy simulation: Towards a fit-for-purpose modeling strategy," Energy Build., vol. 121, pp. 188-204, 2016.

[9] T. Hong, D. Yan, S. D'Oca, and C. fei Chen, "Ten questions concerning occupant behavior in buildings: The big picture," Build. Environ., vol. 114, pp. 518-530, 2017.

[10] C. Peng, D. Yan, R. Wu, C. Wang, X. Zhou, and Y. Jiang, "Quantitative description and simulation of human behavior in residential buildings," Build. Simul., vol. 5, no. 2, pp. 85-94, 2012.

[11] T. S. Larsen, H. N. Knudsen, K. Gram-hanssen, H. Brohus, and J. Rose, "Occupants influence on the energy consumption of Danish domestic buildings - State of the art," Vbnaaudk, no. 110, p. 77, 2010.

[12] R. V. Andersen, B. Olesen, and J. Toftum, "Simulation of the Effects of Occupant Behaviour on Indoor Climate and Energy Consumption," Clima 2007 WellBeing Indoors, no. January, p. 7, 2007. 
[13] J. Charmes, "Time use across the world: Findings of a world compilation of time-use surveys," no. September, 2015.

[14] Eurostat, Harmonised European time use surveys: 2008 Guidelines. 2009.

[15] L. Schipper, S. Bartlett, D. Hawk, and E. Vine, "Linking Life-Styles And Energy Use: A Matter Of Time," Annu. Rev. Energy Environ., vol. 14, no. 1, pp. 273-320, 1989.

[16] U. Wilke, "Probabilistic Bottom-up Modelling of Occupancy and Activities to Predict Electricity Demand in Residential Buildings," PhD Thesis, vol. 5673, p. 172, 2013.

[17] U. Wilke, F. Haldi, J. L. Scartezzini, and D. Robinson, "A bottom-up stochastic model to predict building occupants' time-dependent activities,” Build. Environ., vol. 60, pp. 254-264, 2013.

[18] B. Yu, J. Zhang, and A. Fujiwara, "A household time-use and energy-consumption model with multiple behavioral interactions and zero consumption," Environ. Plan. B Urban Anal. City Sci., vol. 40, no. 2, pp. 330-349, 2013.

[19] J. Torriti, "Understanding the timing of energy demand through time use data: Time of the day dependence of social practices," Energy Res. Soc. Sci., vol. 25, pp. 37-47, 2017.

[20] B. Anderson, "Laundry, energy and time: Insights from 20 years of time-use diary data in the United Kingdom,” Energy Res. Soc. Sci., vol. 22, pp. 125-136, 2016.

[21] J. Tanimoto, A. Hagishima, and H. Sagara, "Cooling Load Simulation Considering Actual Variation Of Inhabitants' Behavior Accurate Estimation Of Urban Maximum Energy Requirement," in 9th International IBPSA Conference, 2005, pp. 1205-1212.

[22] J. Tanimoto, A. Hagishima, and H. Sagara, "Validation of probabilistic methodology for generating actual inhabitants' behavior schedules for accurate prediction of maximum energy requirements," Energy Build., vol. 40, no. 3, pp. 316-322, 2008.

[23] I. Richardson, M. Thomson, and D. Infield, "A high-resolution domestic building occupancy model for energy demand simulations,” Energy Build., vol 40, no. 8, pp. 1560-1566, 2008.

[24] D. Aerts, J. Minnen, I. Glorieux, I. Wouters, and F. Descamps, "A method for the identification and modelling of realistic domestic occupancy sequences for building energy demand simulations and peer comparison," Build. Environ., vol. 75, pp 67-78, 2014.

[25] G. Buttitta, W. Turner, and D. Finn, "Clustering of Household Occupancy Profiles for Archetype Building Models,” Energy Procedia, vol. 111, no. September 2016, pp. 161-170, 2017.

[26] J. Widén, M. Lundh, I. Vassileva, E. Dahlquist, K. Ellegård, and E. Wäckelgård, "Constructing load profiles for household electricity and hot water from time-use data-Modelling approach and validation," Energy Build., vol. 41, no. 7, pp. 753-768, 2009.

[27] D. Fischer, A. Härtl, and B. Wille-Haussmann, "Model for electric load profiles with high time resolution for German households," Energy Build., vol. 92, pp. 170-179, 2015.

[28] J. Tanimoto, A. Hagishima, and H. Sagara, "Validation of probabilistic methodology for generating actual inhabitants' behavior schedules for accurate prediction of maximum energy requirements," Energy Build., vol. 40, no. 3, pp. 316-322, 2008.

[29] J. Widén, A. M. Nilsson, and E. Wäckelgård, "A combined Markov-chain and bottom-up approach to modelling of domestic lighting demand," Energy Build., vol. 41, no. 10, pp. 1001-1012, 2009.

[30] S. De Lauretis, F. Ghersi, and J.-M. Cayla, "Energy consumption and activity patterns: An analysis extended to total time and energy use for French households," Appl. Energy, vol. 206, pp. 634-648, 2017.

[31] M. Jalas and J. K. Juntunen, "Energy intensive lifestyles: Time use, the activity patterns of consumers, and related energy demands in Finland," Ecol. Econ., vol. 113, pp. 51-59, 2015.

[32] Y.-S. Chiou, K. M. Carley, C. I. Davidson, and M. P. Johnson, "A high spatial resolution residential energy model based on American Time Use Survey data and the bootstrap sampling method," Energy Build., vol. 43, no. 12, pp. 3528-3538, 2011.

[33] J. Bonke, "Tax-reforms, normal and actual working hours and welfare in the beginning of the 20th's Denmark,” Electron. Int. J. Time Use Res., vol. 13, no. 1, pp. 91-108, 2016.

[34] J. Bonke, "Time and Welfare (in Danish)," Copenhagen, Denmark, 2002. 
[35] J. Bonke and P. Fallesen, "The impact of incentives and interview methods on response quantity and quality in diary- and booklet-based surveys," Surv. Res. Methods, vol. 4, no. 2, pp. 91-101, 2010.

[36] "Labour, income and wealth - Statistics Denmark." [Online]. Available: http://www.dst.dk/en/Statistik/emner/arbejde-indkomst-og-formue. [Accessed: 17-Oct-2017].

[37] V. M. Barthelmes, R. Li, R. K. Andersen, W. Bahnfleth, S. P. Corgnati, and C. Rode, "Profiling Occupant Behaviour in Danish Dwellings using Time Use Survey Data - Part I: Data Description and Activity Profiling," in COBEE, 2018.

[38] E. L. Kaplan and P. Meier, "Nonparametric Estimation from Incomplete Observations Nonparametric Estimation From Incomplete Observations," Source J. Am. Stat. Assoc., vol. 5313481, no. 282, pp. 457-481, 1958.

[39] J. Kishore, M. Goel, and P. Khanna, "Understanding survival analysis: Kaplan-Meier estimate", Int. J. Ayurveda Res., vol. 1, no. 4, p. 274, 2010.

[40] A. Marszal-Pomianowska, P. Heiselberg, and O. Kalyanova Larsen, "Household electricity demand profiles - A high-resolution load model to facilitate modelling of energy flexible buildings," Energy, vol. 103, pp. 487-501, 2016.

[41] V. M. Barthelmes, R. Li, R. K. Andersen, W. Bahnfleth, S. P. Corgnati, and C. Rode, "Profiling Occupant Behaviour in Danish Dwellings using Time Use Survey Data - Part II. Time-related Factors and Occupancy," in COBEE, 2018.

[42] US Department of Energy, "EnergyPlus” [Online]. Available: https://energyplus.net/ [Accessed: 19Oct-2017].

[43] US Department of Energy, "Residential Buildings Integration _ Department of Energy." [Online]. Available: https://energy.gov/eere/buildings/residential-buildings-integration. [Accessed: 19-Oct-2017]. 